\title{
Iterative methods for generalized split feasibility problems in Banach spaces
}

\author{
QAMRUl HASAN ANSARI ${ }^{1,2}$ and AISHA REHAN ${ }^{1}$
}

\begin{abstract}
.
Inspired by the recent work of Takahashi et al. [W. Takahashi, H.-K. Xu and J.-C. Yao, Iterative methods for generalized split feasibility problems in Hilbert spaces, Set-Valued Var. Anal., 23 (2015), 205-221], in this paper, we study generalized split feasibility problems (GSFPs) in the setting of Banach spaces. We propose iterative algorithms to compute the approximate solutions of such problems. The weak convergence of the sequence generated by the proposed algorithms is studied. As applications, we derive some algorithms and convergence results for some problems from nonlinear analysis, namely, split feasibility problems, equilibrium problems, etc. Our results generalize several known results in the literature including the results of Takahashi et al. [W. Takahashi, H.-K. Xu and J.-C. Yao, Iterative methods for generalized split feasibility problems in Hilbert spaces, SetValued Var. Anal., 23 (2015), 205-221].
\end{abstract}

\section{REFERENCES}

[1] Alber, Y. I., Metric and generalized projection operators in Banach spaces: Properties and applications, in Theory and Applications of Nonlinear Operators of Accretive and Monotone Type (A. G. Kartsatos, Ed.), Lecture Notes in Pure and Appl. Math., 178, Marcel Dekker, New York, 1996, pp. 15-50

[2] Ansari, Q. H., Topics in Nonlinear Analysis and Optimization, World Education, Delhi, 2012

[3] Ansari, Q. H. and Rehan, A., Split feasibility and fixed point problems, in Nonlinear Analysis: Approximation Theory, Optimization and Applications, (Q. H. Ansari, Ed.), Birkhäuser, Springer, New Delhi, Heidelberg, New York, London, 2014, pp. 231-280

[4] Aoyama, K. Kimura, Y. and Takahashi, W., Maximal monotone operators and maximal monotone functions for equilibrium problems, J. Convex Anal., 15 (2008), 395-409

[5] Aoyama, K., Kohsaka, F. and Takahashi, W., Three generalizations of firmly nonexpansive mappings: Their relations and continuous and properties, J. Nonlinear Convex Anal., 10 (2009), 131-147

[6] Browder, F. E., Semicontractive and semiaccretive nonlinear mappings in Banach spaces, Bull. Amer. Math. Soc., 74 (1968), 660-665

[7] Byrne, C., Iterative oblique projection onto convex sets and the split feasibity problem, Inverse Probl., 18 (2002), $441-453$

[8] Byrne, C., A unified treatment of some iterative algorithms in signal processing and image reconstruction, Inverse Probl., 20 (2004), 103-120

[9] Byrne, C., Censor, Y., Gibali, A. and Reich, S., The split common null point problem, J. Nonlinear Convex Anal., 13 (2012), 759-775

[10] Ceng, L.-C., Ansari, Q. H. and Yao, J.-C., Relaxed extragradient methods for finding minimum-norm solutions of the split feasibility problem, Nonlinear Anal., 75 (2012), No. 4, 2116-2125

[11] Cegielski, A., General method for solving the split common fixed point problem, J. Optim. Theory Appl., 165 (2015), 385-404

[12] Censor, Y., Bortfeld, T., Martin, B. and Trofimov, A., A unified approach for inversion problems in intensitymodulated radiation therapy, Phys. Med. Biol., 51 (2006), 2353-2365

[13] Chidume, C., Geometric Properties of Banach Spaces and Nonlinear Iterations, Springer-Verlag, London, 2009

Received: 04.11.2015; In revised form: 20.08.2016; Accepted: 24.08.2016

2010 Mathematics Subject Classification. 49J40, 49J52, 47J20.

Key words and phrases. Generalized split feasibility problems, generalized nonspreading mappings, fixed point problems, iterative methods, maximal-monotone set-valued mappings, relative resolvent operators, convergence analysis.

Corresponding author: Qamrul Hasan Ansari; qhansari@gmail.com 
[14] Goebel, K. and Kirk, W. A., Topics on Metric Fixed-Point Theory, Cambridge Studies in Advanced Mathematics, Cambridge University Press, Cambridge, 1990

[15] Hsu, M.-H., Takahashi, W. and Yao, J.-C., Generalized hybrid mappings in Hilbert spaces and Banach spaces, Taiwanese J. Math., 16 (2012), No. 1, 129-149

[16] Kamimura, S. and Takahashi, W., Strong convergence of a proximal-type algorithm in a Banach space, SIAM J. Optim. 13 (2003), No. 3, 938-945

[17] Khan, A. R., Abbas, M. and Shehu, Y., A general convergence theorem for multiple-set split feasibility problem in Hilbert spaces, Carpathian J. Math., 31 (2015), 349-357

[18] Kohsaka, F. and Takahashi, W., Existence and approximation of fixed points of firmly nonexpansive-type mappings in Banach spaces, SIAM J. Optim., 19 (2008), No. 2, 824-835

[19] Kohsaka, F. and Takahashi, W., Fixed point theorems for a class of nonlinear mappings related to maximal monotone operators in Banach spaces, Arch. Math. (Basel), 91 (2008), 166-177

[20] Kocourek, P., Takahashi, W. and Yao, J.-C., Fixed point theorems and ergodic theorems for nonlinear mappings in Banach spaces, Adv. Math. Econ., 15 (2011), 67-88

[21] Rockafellar, R. T., On the maximality of sums of nonlinear monotone operators, Trans. Amer. Math. Soc., 149 (1970), 75-88

[22] Reich, S., A weak convergence theorem for the alternating method with Bregman distances, in Theory and Applications of Nonlinear Operators of Accretive and Monotone Type (A. G. Kartsatos, Ed.), Lecture Notes in Pure and Appl. Math., 178, Marcel Dekker, New York, 1996, pp. 313-318

[23] Takahashi, W., Nonlinear Functional Analysis, Fixed Point Theory and its Applications, Yokohama Publishers, Yokohama, 2000

[24] Takahashi, W., Introduction to Nonlinear and Convex Analysis, Yokohama Publishers, Yokohama, 2000

[25] Takahashi, W., The split feasibility problem in Banach spaces, J. Nonlinear Convex Anal., 15 (2014), 1349-1355

[26] Takahashi, W., The split common null point problem in Banach spaces, Arch. Math., 104 (2015), 357-365

[27] Takahashi, W., Xu, H.-K. and Yao, J.-C., Iterative methods for generalized split feasibility problems in Hilbert spaces, Set-Valued Var. Anal., 23 (2015), 205-221

[28] Takahashi, W. and Yao, J.-C., Strong convergence theorems by hybrid methods for the split common null point problem in Banach spaces, Fixed Point Theory Appl., 2015 (2005), Article ID 87

[29] Takahashi, W. and Zembayashi, K., Strong and weak convergence theorems for equilibrium problems and relatively nonexpansive mappings in Banach spaces, Nonlinear Anal., 70 (2009), 45-57

[30] Xu, H.-K., Inequalities in Banach spaces with applications, Nonlinear Anal., 16 (1991), 1127-1138

[31] Xu, H.-K., Iterative methods for the split feasibility problems in infinite-dimensional Hilbert spaces, Inverse Probl., 26 (2010), Article ID 105018

\author{
${ }^{1}$ Department OF MATHEMATiCs \\ Aligarh MusLim University \\ ALIGARH, INDIA \\ E-mail address: qhansariegmail.com \\ E-mail address: ai shashaheen370@gmail.com
}

${ }^{2}$ Department of MATHEMATiCs and Statistics

King Fahd University of Petroleum \& Minerals

DHAHRAN, SAUDi ARABIA

E-mail address: qhansari@gmail.com 